\title{
A LUTA PELA TERRA E A EDUCAÇÃO DO CAMPO: O CASO DO ASSENTAMENTO ZÉ MARCOLINO NO CARIRI PARAIBANO
}

\author{
THE FIGHT FOR LAND AND EDUCATION OF THE FIELD: \\ THE CASE OF THE SETTLEMENT ZÉ MARCOLINO \\ IN CARIRI PARAIBANO
}

Maria Socorro Silva ${ }^{1}$

Geovânio Lima Batista

\section{RESUMO}

A luta pela terra no Brasil inicia-se desde a nossa colonização com a formação do latifúndio e a exploração de negros e indígenas, e isso se aprofunda com a constituição do campesinato espoliado pela opressão e da terra pelas oligarquias agrárias. Esse processo vai ocorrer também no Assentamento Zé Marcolino no Cariri Paraibano. O estudo teve como objetivo geral identificar a formação e organização do Assentamento na luta pela terra e pela escola, e qual a percepção que os diferentes sujeitos têm sobre a organização e a escola. A abordagem qualitativa na perspectiva descritiva (Minayo, 1996), orientou todo o percurso metodológico num diálogo permanente com o método dialético. A luta pela Educação do Campo tem possibilitado, através da organização do Assentamento e do protagonismo das mulheres, gerar grandes transformações na comunidade: construção da escola, parcerias, mutirões, currículo contextualizado vinculando sua prática a cultura da comunidade.

Palavras-chaves: Luta pela Terra. Educação do Campo. Organização Social. Assentamento Zé Marcolino.

\section{ABSTRACT}

The struggle for land in Brazil begins from our settlement with the formation of large estates and the exploitation of blacks and indigenous, and that deepens with the constitution of the peasantry dispossessed by oppression and land by the agrarian oligarchies. This process will also occur on the Settlement ZéMarcolino in CaririParaibano. Our study, we aimed to identify the training and

\footnotetext{
${ }^{1}$ Doutora em Educação pela UFPE. Professora da UFCG/CDSA/Unidade Acadêmica de Educação do Campo. Professora do PPGE Educação. Membro do Nupeforp e da Resab. e-mail: socorrosilva@ufcg.edu.br

${ }^{2}$ Mestrando em Educação pela UFCG. Licenciado em Educação do Campo pela UFCG/CDSA. Membro do núcleo de estudos e pesquisas em educação do campo, formação de professores/as e prática pedagógica. e-mail: geovaniolimabatista@gmail.com
} 
organization of the settlement in the struggle for land and school, and the perception that the different subjects have on these processes. The qualitative approach in descriptive perspective (Minayo,1997), directed all the methodological itinerary in an ongoing dialogue with the dialectical method. The struggle for the field of education has allowed, through the organization of the settlement and the role of women, generate major changes in the community, who managed to build their own school through partnership and joint efforts for training access to a contextual education, linking their practice at the community culture universe.

Keywords: Fight for Earth. Rural Education. Social Organization. Settlement ZéMarcolino.

\section{INTRODUÇÃO}

Este trabalho teve como finalidade realizar o mapeamento da trajetória de formação e desenvolvimento do Assentamento Zé Marcolino, localizado numa interseção entre os municípios de Prata, Sumé e Amparo no Cariri Paraibano, pondo em evidência as construções políticas realizadas pelos sujeitos da comunidade, bem como o seu processo de mobilização para construção e manutenção de uma escola no assentamento.

Nesta perspectiva, várias foram as razões que contribuíram na definição de nosso tema, sobretudo, o nosso interesse em ampliar os estudos e pesquisas sobre o papel dos movimentos sociais do campo para construção da Escola do Campo, principalmente no contexto do Cariri Ocidental Paraibano, daí a escolha pelo Assentamento Zé Marcolino ${ }^{3}$.

A escolha deste assentamento surgiu a partir de uma palestra ministrada por uma liderança do assentamento, durante um evento realizado pelo curso de Licenciatura em Educação do Campo, na Universidade Federal de Campina Grande (UFCG), no Centro de Desenvolvimento Sustentável do Semiárido (CDSA) - Campus Sumé-PB. Na ocasião, a referida líder apresentou a história da luta pela Educação do Campo desencadeada pelos moradores que, insatisfeitos pela inexistência de escola na comunidade, resolveram construir sua própria escola. Esse foi nosso primeiro contato com a luta daquela comunidade, o que nos deixou curiosos para entender como se deu essa luta e qual a articulação entre a luta pela terra e a escola.

\footnotetext{
${ }^{3} \mathrm{O}$ nome Zé Marcolino foi dado ao assentamento em homenagem ao cantor e poeta sumeense, em especial sua música, Serrote Agudo, o título da música faz referência ao nome da fazenda desapropriada para formação do referido assentamento.
} 
Outra motivação emergiu do percurso formativo no curso de Licenciatura em Educação do Campo, que por sua identidade e origem nos movimentos sociais, suscita nos seus estudantes a reflexão sobre como a concepção e as políticas de Educação do Campo se articulam com as lutas e organizações sociais campesinas, numa perspectiva de transformação da realidade política, social e educacional, visto que:

A concepção de Educação do Campo que temos trabalhado refere-se a uma multiplicidade de experiências educativas desenvolvidas por diferentes instituições, que colocaram como referência para suas propostas pedagógicas uma nova concepção de campo, de educação e do papel da escola. Assim, a identidade dos sujeitos sociais do campo em sua diversidade que engloba os espaços da floresta, da pecuária, das minas, da agricultura, dos pescadores, dos caiçaras, ribeirinhos, quilombolas e extrativistas, conforme posto pela Resolução CNE 01 de 2001, tornase fundante para reivindicação de políticas educacionais e elaboração das diversas práticas educativas (SILVA, 2006, p. 61).

Com base nisto, tivemos como objetivo geral desta pesquisa identificar o itinerário organizativo do assentamento Zé Marcolino na inter-relação da luta pela terra e pela escola; e como objetivo específico discutir a questão agrária no Brasil e no Cariri Paraibano; compreender o processo de formação e organização do Assentamento; compreender o sentido da organização e da escola para o assentamento e os assentados e identificar a percepção dos assentados e das lideranças sobre a Educação do Campo. Todos esses elementos contribuíram para organização da pesquisa e definiram o referencial, os procedimentos e instrumentos a serem utilizados para nos aproximar do objeto da pesquisa.

\section{CATEGORIAS ANALÍTICAS DO TRABALHO}

A análise e interpretação do trabalho se orientou a partir de algumas categorias analíticas, Minayo (2004), esclarece que os conceitos mais importantes dentro de uma teoria são as categorias. A autora distingue categorias analíticas e categorias empíricas. As categorias analíticas são aquelas que retêm as relações sociais fundamentais e podem ser consideradas balizas para o conhecimento do objeto nos seus aspectos gerais. As categorias empíricas são aquelas construídas com finalidade operacional, visando ao trabalho de campo (a fase empírica) ou a partir do trabalho de campo. Elas têm a propriedade de conseguir apreender as determinações e as especificidades que se expressam na realidade empírica (p. 93 - 94). 
Como categorias analíticas que nos ajudaram a entender melhor o objeto de pesquisa trabalhamos com: Organização social, Educação Popular e Educação do Campo. Essas categorias dialogaram todo o tempo com os conceitos de questão agrária, movimentos sociais e assentamento como definições importantes que interagem com as categorias para a compreensão do tema. Assim, passamos a detalhar como entendemos essas categorias durante todo o trabalho.

\title{
a) Organização Social
}

A ideia de organização social está ligada ao processo social, à ideia de mudança, de arranjo do comportamento das pessoas e grupos na construção da vida social. Possui um propósito social e estabelece relações entre os membros do grupo, entre grupos ou entre pessoas, que se localizam de diferentes maneiras na estrutura social e vivenciam ou não situações de exploração, opressão e discriminação.

Na perspectiva marxista as organizações sociais são determinadas pelo lugar que as pessoas ou grupos encontram-se na estrutura social na forma de produção e reprodução da vida. A fase de desenvolvimento das forças produtivas materiais forma a estrutura econômica da sociedade, e estabelece relações sociais e formas de consciência social. Assim, as relações de produção, os meios de produção e as classes sociais estruturam e organizam a sociedade, portanto,

\begin{abstract}
A situação econômica é a base, mas os diferentes fatores da superestrutura que se levanta sobre ela - as formas políticas da luta de classes e seus resultados, as constituições que, uma vez vencida uma batalha, a classe dominante redige, etc., as formas jurídicas, e inclusive os reflexos de todas essas lutas no cérebro dos que nela participam as teorias políticas, jurídicas, filosóficas, as ideias religiosas e o desenvolvimento ulterior que as leva a converter-se num sistema de dogmas - também exercem sua influência sobre o curso das lutas históricas e, em muitos casos, determinam sua forma como fator predominante (MARX e ENGELS, 1986b, p. 28).
\end{abstract}

$\mathrm{Na}$ totalidade social diferentes aspectos, que não apenas, a produção econômica, determinam a dinâmica das classes, e suas relações, pois mesmo os que se encontram na mesma condição de subordinação, assegura uma experiência comum, que possibilite identidade e um pertencimento frente aos outros segmentos sociais. 


\section{Revista \\ Debates Insubmissos}

Para o pensamento marxista as classes sociais são grandes agrupamentos humanos que se definem a partir da posição ocupada pelos indivíduos nas relações sociais de produção como proprietários ou não proprietários dos meios de produção. Assim, dependendo do tipo de trabalho realizado, as condições em que a força de trabalho é empregada, têm um conjunto heterogêneo nas classes trabalhadoras do campo ${ }^{4}$, como por exemplo, enquanto o assalariado rural vende sua força de trabalho, o produtor familiar se vincula diretamente com a pequena propriedade $^{5}$, e possui uma relativa autonomia sobre a organização de sua produção.

Essa diversidade dos sujeitos suscita várias organizações e formas de lutas para o enfrentamento dos desafios postos pelo capitalismo agrário. Tais desafios podem ser entendidos sob diversas formas: luta pela terra, reivindicação de crédito e assistência técnica para a produção, melhoria da infraestrutura (estradas, eletrificação, cisternas, sistemas de irrigação), garantia dos serviços sociais básicos (educação e saúde), dentre outros.

De acordo com Gohn (1995), na composição da organização social, será o conflito de interesses e necessidades gerado pelo capital entre as diferentes classes ${ }^{6}$ que irá gerar a necessidade de representação e organização, e, portanto, surgem os movimentos sociais, da materialidade da vida e das relações de poder, que geram conflitos sociais e ideológicos de dominação/libertação. Assim, os movimentos sociais devem ser entendidos como ações coletivas orientadas para a promoção de mudanças, no todo ou em parte, em instituições, condições ou relações sociais na perspectiva da contra hegemonia.

Não existe um consenso no conceito de movimento social. Vários autores tentam enumerar um maior conjunto de critérios para caracterizar um movimento social. Gohn (1995, p. 44) assim define movimentos sociais: "São ações coletivas de caráter sociopolítico, construídas por atores sociais pertencentes a diferentes classes e camadas sociais". Eles politizam suas demandas e criam um campo político de força social na sociedade civil. Suas

\footnotetext{
${ }^{4}$ Como as classes não são homogêneas, os movimentos também não o são, nem do ponto de vista de sua composição, nem de suas demandas.

${ }^{5}$ Os estudos posteriores dos marxistas irão aprofundar a questão dos movimentos sociais de uma forma mais heterogênea que o sindicato e o partido, além de ter uma visão mais heterogênea, ao considerar a classe média e o campesinato dentro desta perspectiva de classe trabalhadora.

${ }^{6}$ Para Marx a classe social dominante no âmbito da infraestrutura será também a classe dominante no nível da superestrutura social.
} 
ações estruturam-se a partir de repertórios criados sobre temas e problemas em situações de conflitos, litígios e disputas. As ações desenvolvem um processo social e político-cultural que cria uma identidade coletiva ao movimento, a partir de interesses em comum. Esta identidade decorre da força do princípio da solidariedade e é construída a partir da base referencial de valores culturais e políticos compartilhados pelo grupo.

A concepção de organização social parte da literatura assinalada por Silva (2002), Julião (2009) Gohn (1997), Fernandes (2006) e Arroyo e Fernandes (1999). Os referidos autores convergem sobre a perspectiva de que os movimentos sociais se constituem enquanto forças sociais, que possibilitam, através de suas ações políticas e ideológicas, mudanças no cenário político em que atuam e desencadeiam os conflitos sociais em meio aos interesses ideológicos entre diferentes setores e classes.

Os referidos autores elevam os sujeitos que formam os movimentos sociais a categoria de atores/atrizes, no processo de lutas pelos seus direitos, a partir de uma consciência crítica da realidade e a partir da formação de identidades coletivas (re)constroem o espaço em que vivem e lutam.

Gohn (2005, p. 31-2) traçou um panorama dos movimentos sociais, apontando dez eixos temáticos, tais como eles teriam se apresentado na trajetória dos movimentos sociais no Brasil: (1) lutas e conquistas por condições de habitabilidade na cidade, nucleadas pela questão da moradia; (2) mobilização popular em torno de estruturas institucionais de participação na estrutura político-administrativa da cidade; (3) mobilizações e movimentos de recuperação das estruturas ambientais, físico-espaciais, equipamentos e serviços coletivos; (4) mobilizações e movimentos contra o desemprego; (5) movimentos de solidariedade e apoio a programas com meninos e meninas de rua; (6) mobilizações e movimentos dos sem-terra; (7) movimentos etnorraciais; (8) movimentos que envolvem questões de gênero; (9) os diversos movimentos rurais; e (10) movimentos contra políticas neoliberais e efeitos da globalização.

Do ponto de vista do rural, as organizações sociais assumem diferentes arranjos coletivos: movimentos de luta por terra, movimentos identitários (mulheres, negros, juventude, quilombolas, dentre outros), associações, cooperativas, sindicatos, pastorais. Para 


\section{Revista \\ Debates Insubmissos}

Rios (1986, p. 789), as motivações podem variar entre os movimentos camponeses das sociedades tradicionais ou desenvolvidas e os movimentos de agricultores, dependendo da forma como são conceituados. Segundo o autor, os movimentos camponeses seriam protagonizados por indivíduos que não têm a posse da terra e que são explorados por latifundiários que lhes pagam baixa remuneração e não lhes permitem cultivar alimentos; geralmente, lutam por acesso à terra, por sua partilha, ou pelo direito a uma melhor remuneração.

Os movimentos de agricultores/as familiares por sua vez, envolvem atores sociais detentores de terra, pequenas propriedades rurais, muitas delas familiares, e tais movimentos visam à obtenção de melhores preços, subsídios, incentivos e crédito, e se voltam contra os especuladores, os intermediários, os donos dos meios de transporte, de armazenamento ou de financiamento.

\section{b) Educação Popular}

A Educação Popular, entendida enquanto uma teoria e prática da educação, está vinculada às classes populares e suas lutas pela emancipaçãocontra as assimetrias sociais. Desse modo, a Educação Popular retoma vigência e sentido, porque é necessário recuperar seu papel de contribuir para a emancipação humana, no sentido de construção de autonomia, de uma nova sociabilidade na qual os seres humanos sejam realmente livres, e tenham acesso a todas as produções materiais e imateriais que constituem o patrimônio da humanidade para além das limitações e alienação imposta pelo capitalismo.

[...] a emergência da concepção de Educação Popular pode e deve ser associada ao fato de as classes populares existirem e às suas condições de vida; às opções que as elites tiveram de rumos para o desenvolvimento do Brasil; ao movimento internacional dos trabalhadores; às ideias pedagógicas predominantes num determinado período; ao desejo e esperança de construção de um mundo melhor; e às possibilidades de, via educação, contribuir para a emancipação das classes subalternas e para a sua entrada no cenário político (PALUDO 2001, p. 85).

A revisão da literatura evidencia a Educação Popular como uma teoria educacional, uma prática pedagógica e um movimento de cultura popular, que tem a finalidade de formação humana. Elencamos as contribuições de Freire (2011), Silva (2002) e Paludo (2008) na análise deste referencial e na reflexão do surgimento da Educação popular como 
umaformação de base, para além de uma proposta de educação para os pobres, porém vinculada aos princípios da autonomia, da emancipação, da participação democrática e como possibilidade de acesso à cultura, com a perspectiva de elevar o nível de participação na política e, sobretudo, como princípio de consciência crítica dos educandos e como principal referência a perspectiva de protagonismo do homem descrito por Paulo Freire, que é entendida não só como um direito de cidadania, mas como a necessidade de construir caminhos para um processo educativo, político, econômico, social e cultural, na formação autônoma dos sujeitos que ao socializar-se constroem o conhecimento e se humanizam.

A Educação Popular, na ótica de Freire, se faz popular pelo potencial de organização da classe trabalhadora, possui em sua essência a contestação do sistema político e da ordem econômica vigente. Segundo o educador, sair da condição de oprimido não é simplesmente deslocar-se para a função de opressor, mas propor uma nova relação social em que haja igualdade entre homens e mulheres projetando um bem comum.

Desse modo, a Educação Popular retoma vigência e sentido, porque é necessário recuperar seu papel de contribuir para a emancipação humana, no sentido de construção de autonomia, de uma nova sociabilidade na qual os seres humanos sejam realmente livres, e tenham acesso a todas as produções materiais e imateriais que constituem o patrimônio da humanidade para além das limitações e alienação imposta pelo capitalismo.

Ao resgatar o contexto de constituição da Educação Popular como concepção pedagógica, buscou-se identificar uma possível vinculação desta com a luta por uma Educação do Campo. O que permitirá compreender os princípios da Educação Popular como determinantes da luta e constituição da Educação do Campo, pois ao assumirem tal demanda os povos do campo, através dos Movimentos Sociais Populares do Campo, firmam-se em suas diversas experiências formativas no sentido de se contraporem ao Projeto de Campo do Agronegócio e ao modelo de escola da Educação Rural.

\section{c) Educação do Campo}

A Educação do Campo, entendida enquanto conceito e prática pedagógica referem-se às várias iniciativas de educação não escolar e de escolarização dos sujeitos do campo. A 


\section{novistet

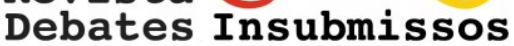

Educação do Campo como uma prática pedagógica emerge da prática social dos sujeitos e movimentos sociais do campo brasileiro, de sua cultura, de sua produção, do seu trabalho, de sua relação com o mundo e com a vida, portanto como uma prática sociopolítica e cultural. Assim:

A Educação do Campo é uma prática educativa que acontece nos espaços escolares e não escolares, na perspectiva da formação e emancipação humana. Por isto, se expressa em: Ações formais: escolarização básica e superior desenvolvida pelo sistema de ensino nas esferas público e privada; ações não formais: formação política, sindical, técnica, produtiva, religiosa, cultural desenvolvida por instituições governamentais de extensão rural, assistência técnica, pesquisa e por órgãos não governamentais da sociedade civil; ações informais: as que se desenvolvem na família, na comunidade, nas manifestações culturais, nos meios de comunicação, no trabalho, muitas vezes espontâneas, vindas não só de organizações, mas, sobretudo de pessoas, que na vida cotidiana promovem ações educativas (SILVA, 2009, p.100 grifo da autora).

$[\ldots]$

A emergência do debate da Educação do Campo na agenda pública contemporânea ocorre a partir da década de 1990, com diferentes ações, dentre as quais destacamos: inserção na agenda pública governamental do debate das políticas específicas, como uma questão de interesse nacional e como direito desses povos; a expansão e articulação nacional dos Centros de Formação Familiar em Alternância; o fortalecimento da articulação entre as organizações não governamentais que trabalham comescolarização no campo; as experiências alternativas de escolarização em acampamentos e assentamentos da Reforma Agrária; a constituição de Fóruns Estaduais de Educação do Campo e a instituição de programas governamentais específicos do campo, como, por exemplo, o Pronera (SILVA, 2009, p.143).

A autora também destaca que, essas práticas educativas foram se fortalecendo no campo brasileiro a partir da ação das organizações não governamentais, dos movimentos sociais, de docentes que atuavam na Educação Popular, que levaram para as universidades a proposição via extensão e pesquisa. Este movimento se ampliou e se fortaleceu mediante o diagnóstico da exclusão da escolarização dos sujeitos do campo, da precarização e descontextualização da escola existente no campo e da inexistência de uma formação inicial e continuada específica dos profissionais da educação do campo. Portanto,

O termo "Educação do Campo" que estamos tratando nesse texto tem um sentido amplo e complexo, portanto, não deve ser entendido apenas como sinônimo de ensino. Este conceito fundamenta-se na prática educativa que temos desenvolvido nos movimentos sociais, nas diferentes organizações [...] (SILVA, 2009, p. 8).

Historicamente a educação desenvolvida nas escolas do campo descaracteriza as potencialidades e singularidades deste território, por elencar como referência o processo de 


\section{novistet

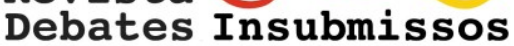

modernização que tem a urbanização como centro e como modelo a ser seguido pelos setores periféricos e campesinos. As escolas rurais sob tal modelo nega a diversidade e as diferentes formas de socialização no campo, promovendo um processo de descaracterização da ação pedagógica no território campesino, pois não suscita uma visão crítica das relações assimétricas existentes na sociedade, tão pouco exerce uma formação libertadora, em que,

[...] o homem pode refletir sobre si mesmo e colocar-se num determinado momento, numa certa realidade: é um ser na busca constante de ser mais e, como pode fazer está autorreflexão, pode descobrir-se um ser inacabado que está em constante busca. Eis aqui a raiz da educação (FREIRE, 2011, p. 34).

Neste sentido, a Educação do Campo no Brasil tem como marco a organização dos Povos do $\mathrm{Campo}^{7}$, no intuito de construir uma proposta pedagógica, de organização do trabalho pedagógico e do currículocontextualizado às necessidades sócio-políticoeconômicas-culturais dos territórios campesinos e quilombolas, o que passa também pela luta por políticas públicas e sociais, pois:

O Movimento da Educação do Campo, em seu processo de mobilização pela afirmação e fortalecimento das práticas pedagógicas das Escolas do Campo, instiga as políticas públicas, a compreenderem o campo como um espaço emancipatório, como um território fecundo de construção da democracia e da solidariedade, e de lutas pelo direito à terra, às águas, à floresta, à soberania alimentar, à saúde, à educação, ao meioambiente sustentável, enfim, um lugar de direitos (SILVA, 2009,p. 98).

A Educação do Campo é fruto das contradições sociais constituída pelos movimentos sociais do campo, possui um marco temporal, histórico e político e pedagógico. Este debate traz ao centro a concepção de educação enquanto direito, possibilita pensar o campo enquanto espaço da multiculturalidade, da exclusão, da expropriação, da desigualdade e da conflitualidade.

\footnotetext{
${ }^{7}$ Utilizamos o termo - "Povos do Campo", conforme posto por Silva (2009) para nos referirmos aos que produzem e reproduzem sua vida numa relação direta com a terra, a floresta e as águas, e sofrem algum tipo de assimetria no campo brasileiro. Povo, conforme esta autora, longe de significar uma homogeneização social, significa a diversidade dos explorados e interditados dentro de uma formação social. Na dimensão social e política,
} 


\title{
3. METODOLOGIA
}

A pesquisa qualitativa proporciona uma aproximação da compreensão do fenômeno nas falas, ações e percepções dos sujeitos, no tocante ao fenômeno. Essa perspectiva nos proporcionou entender as motivações e os significados que os sujeitos do Assentamento, sobretudo as lideranças e professores, atribuem a luta pelas melhorias na qualidade de vida dos assentados, através da luta política, que possibilita o acesso a políticas públicas que proporcionam o desenvolvimento da comunidade e confrontá-las com as percepções dos demais assentados com relação às referidas políticas, nos possibilitando desvendar, sob diferentes olhares, o contexto de sociabilidade em meio à organização do assentamento.

De acordo com Terence (2006, p.2),

\begin{abstract}
$\mathrm{Na}$ abordagem qualitativa, o pesquisador procura aprofundar-se na compreensão dos fenômenos que estuda - ações dos indivíduos, grupos ou organizações em seu ambiente e contexto social - interpretando-os segundo a perspectiva dos participantes da situação enfocada, sem se preocupar com representatividade numérica, generalizações estatísticas e relações lineares de causa e efeito.
\end{abstract}

No tocante ao Assentamento Zé Marcolino, investigamos a luta da comunidade para construção de uma escola e a resistência contra a imposição da política do Estado de fechamento da escola no Assentamento, que promoveu um processo de mobilização, organização e proposição da comunidade assentada, com destaque para a participação das mulheres assentadas. A metodologia dialética nos permitiu entender as relações políticas e sociais construídas no cotidiano do assentamento, amalgamadas pelas contradições das imposições e conflitualidades geradas pelos diferentes atores e instituições envolvidas no processo do assentamento das famílias em sua diversidade de relações com a terra e com a produção.

A aproximação com o método dialético nos ajudou a olhar a totalidade da problemática, que não consistiu apenas em organizar a escola ou a associação, mas os diferentes conflitos e contradições geradas por estes processos, principalmente considerando a forma como a questão fundiária se estruturou no Território do Cariri Paraibano, ao longo da história pela tensão e conflito permanente da hegemonia do latifúndio, imposta pelo latifúndio, a pecuária e o coronelismo e os camponeses que foram ocupando o espaço da 
região,constituindo a produção familiar centrada na relação entre o criatório de ovinos, caprinos, bovinos e a agricultura produtora de alimentos para a família e o mercado interno da região.

Esse referencial teórico-metodológico nos levou a uma série de indagações que nortearam essa pesquisa: qual a origem das pessoas que se inseriram na formação do assentamento? Como se deu este processo? Como isto influenciou a luta pela escola? Como a organização social contribui na formação das demandas para educação do campo no Assentamento Zé Marcolino?

Em um panorama geral, nossa pesquisa fez uma descrição das contradições ocorridas ao longo da história acerca das relações do campesinato brasileiro, com base na revisão da literatura, o que proporcionou a compreensão da questão agrária no Brasil. Conforme Gil (2008. p, 47), as pesquisas descritivas “[...] têm como objetivo primordial a descrição das características de determinada população ou fenômeno ou o estabelecimento de relações entre variáveis". Nosso papel enquanto pesquisador consistiu em identificar as percepções coletivas em meio às identidades dos sujeitos, produzidas a partir da organização política e a luta dos trabalhadores e trabalhadoras do campo.

$\mathrm{Na}$ abordagem qualitativa o campo de pesquisa se constitui enquanto espaço de interação no qual o pesquisador busca compreender o fenômeno em suas condições naturais, portanto, é possível compreender as relações construídas em torno do objeto de pesquisa, proporcionando ao pesquisador a narrativa da análise dos fatos, evidenciando o seu papel na coleta de dados.

Para nos aproximarmos da problemática e das informações, utilizamos diferentes procedimentos e instrumentos. Durante todo o processo de elaboração do projeto e de coleta e análise dos dados adotamos a revisão bibliográfica como um suporte teórico para aprofundamento das discussões sobre o tema abordado, pois de acordo com Severino (2007, p 122) “pesquisa bibliográfica é aquela que se realiza a partir do registro disponível, decorrente de pesquisas anteriores, em documentos impressos como livros artigos, teses, etc.", constituindo-se como eixo orientador para realização de toda a investigação. 


\section{Revista \\ Debates Insubmissos}

Para o aprofundamento do material coletado por estes instrumentos, realizamos entrevistas semiestruturadas, conceituadas como uma combinação entre "perguntas abertas e (ou estruturadas) onde o entrevistado tem a possibilidade de discorrer o tema proposto, sem respostas prefixadas pelo pesquisador" (MINAYO 1996, p. 108). Com moradores do Assentamento, dos quais foram entrevistados: lideranças do Assentamento, membros da associação, diretora da escola, trabalhador posseiro, mães de alunos e as professoras da Escola, com a finalidade de compreendermos e analisarmos suas opiniões acerca de nossas discussões.

Os sujeitos da pesquisa foram assentados e assentadas, e que são diversos em várias dimensões, pois o assentado, em certa medida, é este sujeito que “[...] devido à diversidade social de suas origens, de sua experiência, de sua trajetória e de suas aspirações, tem sido, sociologicamente um sujeito ambíguo" (MARTINS, 2003, p.11). Vive na permanente tensão entre ser trabalhador rural e proprietário titular da terra, além de estarem permanentemente entre os dois mundos.

A vivência no assentamento nos espaços da Associação, da Escola e a ida à casa dos assentados/as, nos possibilitaram momentos de conversa informal e, consequentemente, uma interação com as fontes de informação e com os sujeitos, facilitando a compreensão sobre o objeto estudado.

A problematização das vivências e experiências dos assentados/as na luta pela terra e pela escola foi descrita a partir das observações e das entrevistas realizadas com os sujeitos do Assentamento Zé Marcolino.

O Assentamento Zé Marcolino, abrange na sua extensão os municípios de Sumé, Amparo e da Prata, localizados no território do Cariri Ocidental da Paraíba como demonstra a figura 1 . 
Figura 1 - Representação do Cariri Ocidental e sua localização na Paraíba e no Brasil

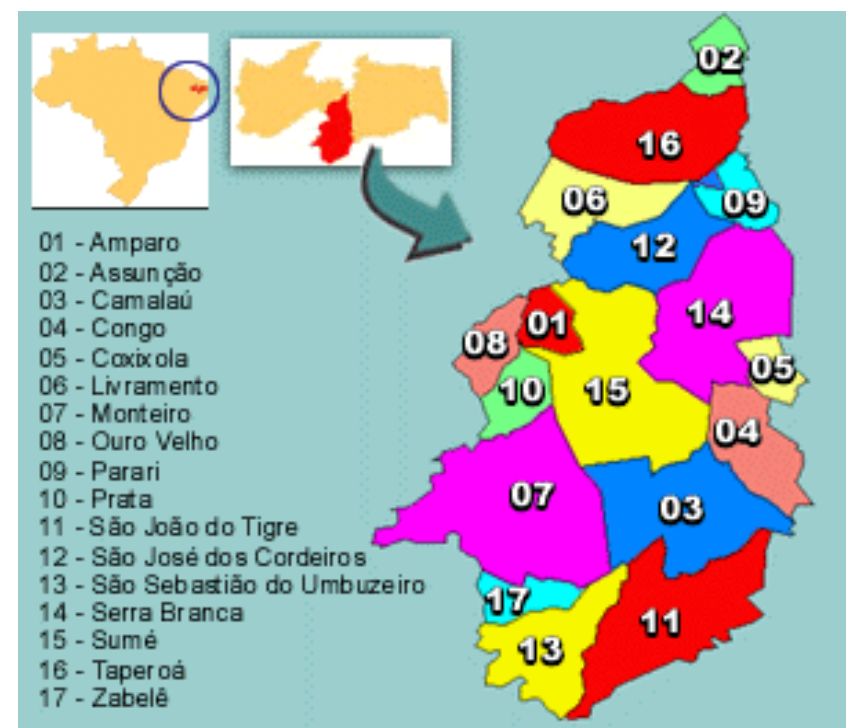

Fonte: IBGE, 2017.

O Assentamento Zé Marcolino abrange quatro agrovilas, sendo duas localizadas no município da Prata, uma em Sumé e uma em Amparo, todas dentro da área da antiga Fazenda

Serrote Agudo, portanto, se relaciona com as políticas de quatro municípios distintos. No caso da escola, esta se localiza na Agrovila, Laginha, no município da Prata.

A referida fazenda foi desapropriada para fins da Reforma Agrária em 1999, e foi entregue ao Instituto Nacional de Colonização e Reforma Agrária (INCRA). Porém, os antigos donos não a desapropriaram de imediato, mesmo após o pagamento da terra, o que gerou uma mobilização para a entrada na terra por parte das famílias, visto que outras já moravam na terra como posseiros.

No final do ano 2000, o Movimento dos Trabalhadores Sem Terra (MST) iniciou um processo de mobilização das famílias assentadas pelo órgão, através de uma ocupação na Sede da Fazenda, para que os mesmos pudessem trabalhar na terra conquistada e pressionar o INCRA para concessão da posse e entrega da terra aos novos donos.

Ao longo do tempo formamos várias parcerias, a primeira foi com o MST, que participou do processo de mobilização das pessoas para formar o acampamento na sede da fazenda, um dia depois o acampamento as coisas começaram a andar, pois o pessoal que tinha arrendado a terra começou a tirar os animais e a gente começou a dividir os lotes (Fala do Presidente da Associação). 
De acordo com esta fala, o processo de mobilização iniciado pelo MST foi fundamental para que as pessoas pudessem ter direito ao acesso à terra, que mesmo após ser indenizada encontrava-se arrendada à terceiros que não saiam da terra para que pudessem produzir, o que não efetivava o processo de assentamento das famílias e o tensionamento entre estas, e as famílias que já se encontravam na terra como posseiros.

Na pesquisa de campo, a dimensão dialética contribuiu para uma aproximação com o contexto e com os diferentes sujeitos, a partir da dinâmica do seu cotidiano no assentamento, na associação e na escola, numa visão de totalidade. Conforme posto por Severino (2007, p.13), neste olhar a "[...] a coleta de dados é feita nas condições naturais onde os fenômenos ocorrem, sendo assim diretamente observados, sem intervenção ou manuseio por parte do pesquisador".

Os dados coletados nos mostraram que estes sujeitos desempenham diferentes papéis no processo de organização do assentamento e da escola, portanto, aplicamos questionários conforme os papéis destes sujeitos no assentamento: lideranças da associação, assentados, professores do assentamento.

\section{a) Lideranças da Associação dos Moradores do Assentamento}

Um primeiro grupo pesquisado foi composto pelas lideranças que compõem a diretoria da Associação dos Moradores. A diretoria da Associação é composta por: 01 presidente, 01 vice-presidente, 02 secretários e 02 tesoureiros. De acordo com o presidente da Associação, a atual diretoria está com um ano de mandato. O presidente nos relatou que cada mandato corresponde a dois anos, que pode ser renovada uma única vez por igual período, caso a chapa seja reeleita. A ocupação dos cargos se deu de forma paritária entre homens e mulheres, ou seja, a diretoria é composta por três homens e três mulheres.

\section{b) As professoras da Escola do Assentamento}

A primeira é Licenciada em Matemática e ocupa também o cargo de diretora da escola, a mesma reside na agrovila de Macacos, município da Prata, e trabalha na escola há 05 (cinco) anos. 
A segunda educadora possui Licenciatura em Biologia, reside na agrovila da Laginha, município da Prata, e atua na escola do assentamento há 03(três) anos, exercendo a docência com a turma da creche.

A terceira educadora possui o curso normal médio, atualmente cursa Pedagogia, também reside na agrovila da Laginha, e atua na escola há 05(cinco) anos atuando na turma do primeiro ciclo do ensino fundamental.

As três professoras assumem também as turmas de Educação de Jovens e Adultos (EJA) no turno da noite.

\section{c) Famílias Pioneiras do Assentamento}

As famílias pioneiras ${ }^{8}$ do Assentamento são constituídas por 29 (vinte e nove) famílias, que residem até os dias atuais na agrovila, das quais aplicamos o questionário com 19 (dezenove) famílias que se encontravam em suas residências no momento da pesquisa, para preenchimento do questionário o critério foi o membro presente na residência que demonstrasse disponibilidade em responder ao instrumento.

Nos procedimentos de reflexão sobre os dados da pesquisa de campo, adotamos a análise de conteúdo como técnica norteadora da análise do material proveniente dos diferentes instrumentos, possibilitando uma análise objetiva e sistemática a respeito de nosso objeto, através da interpretação das expressões e os conteúdos das mensagens colhidas nas entrevistas, buscando uma reflexão aprofundada do sentido atribuído pelos sujeitos, através da interpretação das questões apontadas pelos mesmos no processo de coleta de dados.

Do ponto de vista operacional, a análise de conteúdo parte de uma literatura de primeiro plano para atingir um nível mais aprofundado: aquele que ultrapassa os significados manifestos. Para isso a análise de conteúdo em termos gerais relaciona estruturas semânticas (significantes) com estruturas sociológicas (significados) dos enunciados. Articula a superfície dos textos descrita e analisada com os fatores que determinam suas características:

${ }^{8}$ Estamos denominando de famílias pioneiras, aquelas que participaram do processo de ocupação da terra, e que se encontram na mesma até os dias atuais. 
variáveis psicossociais, contexto cultural, contexto e processo de produção da mensagem (MINAYO, 1992, p. 203).

A análise temática que, de acordo com Minayo (1996, p. 209), “[...] consiste em descobrir os núcleos de sentidos que compõem uma comunicação cuja presença ou frequência signifiquem alguma coisa para o objeto analítico visado", a partir da reflexão acerca da análise temática e seguindo os desdobramentos de suas três etapas, a primeira é a "préanálise" que incide na seleção dos documentos a serem analisados, convergindo com o processo de definição e retomada da hipótese e objetivos iniciais, a partir das descobertas que surgem no universo da coleta de dados.

Na segunda fase da análise temática refere-se à exploração de material que consiste na união dos dados a partir da transformação dos dados brutos, para o processo sistemático dos resultados, permitindo o núcleo de compreensão do texto.

A terceira fase refere-se ao Tratamento dos Resultados Obtidos e Interpretação, nesta fase, adota-se o processo de tratamento dos dados brutos, a partir de operações estatísticos simples ou complexo, possibilitando consideração no tratamento dos dados obtidos. Tais procedimentos permitem a problematização dos dados, possibilitando uma análise teórica, ou novos caminhos que surgem após a leitura do material.

\section{A POSSE DA TERRA GERA A NECESSIDAde DE ORGANizAÇÃo: A ASSOCIAÇÃO DO ASSENTAMENTO}

A Associação dos Assentados da Fazenda Serrote Agudo, foi fundada no ano de 2000, após a efetivação da posse da terra, surgiu à necessidade da organização da comunidade para o acesso as políticas públicas e a infraestrutura no assentamento.

Uma das primeiras reinvindicações e conquista da Associação foi à construção das casas. As casas foram construídas em regime de quatro agrovilas, onde as residências são construídas em um único espaço, formando uma vila de moradores, e não em seus próprios lotes, essa metodologia de agrovilas foi orientada pelo INCRA, e visava facilitar o acesso a projetos de infraestrutura para o Assentamento como energia elétrica e água encanada, 


\section{novistet \\ Debates Insubmissos}

outrofator que contribuiu para formação das agrovilas foi com relação aos interesses e às identidades das pessoas com seus respectivos municípios (Amparo, Prata e Sumé), visto que a área do assentamento faz uma intersecção entre os três municípios:

A comunidade de Formigueiro ficou com a agrovila em Sumé, o pessoal de Cumaru decidiram fazer em Amparo e o pessoal da comunidade de Laginha e Macacos, na Prata. Isso gera uma diversidade muito grande no atendimento das políticas e na negociação com o poder público de três municípios diferentes [...] (Fala de Liderança do Assentamento).

Assim, esse modelo trouxe consigo uma série de problemas e conflitos entre os moradores. De acordo com uma liderança, os lotes de terras ficam distantes das residências dos trabalhadores/as, sendo necessário um longo deslocamento para chegar até a terra, que em alguns casos está mais próxima de outra agrovila. Outro grande problema que causa grandes conflitos, é com relação ao acesso a políticas governamentais, como é o caso do Garantia Safra, pois o acesso ao benefício se dá através de cotas e com a contrapartida do município beneficiário, no entanto, tratando-se do Assentamento Zé Marcolino, todas as famílias obrigatoriamente devem fazer o cadastro em um único município, este deve arcar com a contrapartida das 86(oitenta e seis) famílias beneficiarias, incluindo as famílias residentes em outro município, o que causa tensionamento entre os que residem em diferentes municípios, pois,

[...], isso é um problema dentro do Assentamento, porque o assentamento da gente pega três municípios e pra você ter uma ideia, as DAP do INCRA, só vem num município, se a gente botar no município da Sumé, as DAP passa tudo pra o município de Sumé [...] isso tem gerado muito problema no garantia Safra, porque se as DAP hoje tá no município da Prata, o pessoal do Assentamento todinho tem que vir pra Prata pra o garantia Safra, e quem é que quer pagar a cota dos outro município? (Fala da Liderança Assentada).

Portanto, a metodologia vem proporcionando conflitos no Assentamento, por não ter havido uma discussão mais ampla e profunda sobre o que significa a ocupação da terra, em cada uma dessas formas e no planejamento coletivo, observando as dificuldades que tal metodologia poderia proporcionar no acesso às políticas públicas. $\mathrm{O}$ posseiro reclama que o objetivo da instalação da agrovila, que era facilitar o acesso ao saneamento básico, nunca foi alcançado. 
No que pudemos observar com relação à Associação, percebemos divergências com relação aos moradores e às percepções das lideranças, pois os moradores acreditam que a importância da associação consiste principalmente na captação de recursos.

De acordo com os resultados da pesquisa, $88 \%$ dos moradores afirmam que a captação de recurso e elaboração de projetos é o fator mais importante em meio à associação do Assentamento, já 12\% dos moradores acreditam que a importância da associação diz respeito à organização do Assentamento.

Já uma das lideranças afirma que a importância da Associação consiste no processo de organização da comunidade, que perpassa por momentos de construção coletiva e que possui muita relevância para o desenvolvimento da comunidade, como entidade representativa. "Tudo passa pela associação [...] é a gente que tenta organizar o povo, a gente gosta de usar diferentes metodologias... gosta de trabalhar com grupo de interesse. [...] (Fala de LiderançaAssentada)". Esta fala expressa a importância da Associação na percepção das lideranças, como espaço de organização, de formação de grupos, de parcerias, de aprendizagem de tecnologias sociais.

Quando perguntada sobre essa prática de se trabalhar com grupos de interesses, a mesma revelou que a associação oferece apoio para fomentar projetos de interesses de grupos, como caprinocultores, agricultores, mulheres, dentre outros. A fala da liderança ressalta a prática da silagem ${ }^{9}$, iniciada por um produtor com apoio da Associação, e que atualmente é uma prática comum entre os criadores.

Outra dimensão enfatizada para organização da comunidade também possibilita a elaboração de projetos, a captação de recursos para a produção e infraestrutura no Assentamento, assim, “a Associação é o carro chefe, para ter acesso às políticas públicas, aos benefícios sociais, a captação de recursos para o Assentamento" (Fala de Assentado).

Contudo, percebe-se divergência entre as concepções dos moradores e das lideranças no que tange à importância da associação para o assentamento, pois a maioria dos assentados

\footnotetext{
${ }^{9}$ Técnica de armazenamento de ração no período das chuvas, para servir como suporte forrageiro no período da estiagem.
} 
parte do princípio de que a importância da Associação é a captação de recursos para os associados, já as lideranças acreditam que a importância da entidade consiste na organização da comunidade e que os benefícios são resultantes da organização. Isso evidencia a diferença de concepção do papel que a Associação, enquanto uma organização social ocupa no assentamento, bem como o papel dos assentados nos processos desenvolvidos e nas definições dasações.

\section{QUEM LUTA POR TERRA, QUER ESCOLA}

Caldart (2002) já coloca que uma das grandes marcas da Luta pela Terra é a luta pela Escola. Para esta autora, os desafios do campo em movimento que multiplica as lutas sociais por educação. Por sua vez são estas lutas que vão ajudando a tornar consciente este direito e, aos poucos, vão transformando este direito também em um dever do Estado, e por isto uma prática social e cultural necessária de ser fortalecida, para consolidar um modo de vida e uma visão de mundo: escolas no e do campo não precisam ser algo inusitado, mas sim podem passar a ser um componente efetivo na vida dos povos campesinos.

Isso também ocorreu no Assentamento Zé Marcolino, em 2008 iniciou na comunidade uma grande luta pela escola no Assentamento e que a concretização desta pauta foi possível através da organização dos sujeitos, a partir de uma batalha política desencadeada pelos mesmos, principalmente na autoria das mulheres, que assumiram esta luta como estratégica.

De acordo com as informações coletadas no trabalho de campo, as crianças tinham que se deslocar até a cidade, pois não havia escola no Assentamento, no percurso até a sede do município os estudantes enfrentavam uma série de problemas como: longas distâncias percorridas em transportes inadequados, durante os períodos de chuvas não havia possibilidade de deslocamento, as crianças eram "esquecidas" pelos motoristas, e de acordo com líderes e professoras do Assentamento a educação da cidade oferecia uma formação desconectada com a vida, o trabalho e a cultura do campo. 


\title{
Revista \\ Debates Insubmissos
}

O debate sobre a construção da escola fez parte das reuniões da comunidade, que tinha a finalidade de aplicar os conhecimentos adquiridos nas formações em parceria com a associação do assentamento em prática. Uma das professoras por sua vez afirma:

\begin{abstract}
A Associação não sai da escola, porque desde o começo a gente tem esse vínculo e a Associação nos ajudou muito e continua nos ajudando hoje[...] a prioridade do Assentamento hoje é a escola, então se a gente perder esse contato com a Associação hoje, a gente vai perder muito da escola também, eu não digo assim só de projetos, mas de ajuda de uma boa conversa com os alunos que a Associação faz[...] a escola hoje, ela depende muito da Associação até porque o local onde a escola tá, ele é dá Associação, foi a Associação que conseguiu [...] então é assim um cuidado que a Associação tem com a escola e um cuidado que a escola tem em não perder a Associação inclusive a gente incentiva muito os pais a participarem também, através de reuniões na escola[...]. (Professora do Assentamento).
\end{abstract}

A fala da professora nos revela que a Associação desempenha um papel de parceria com a escola, tanto para sua construção, quanto no convívio com os sujeitos que interagem neste espaço de socialização do saber, neste sentido, além de conseguir captar recurso para a construção da escola, assume o papel de mediar às relações no espaço da escola, no diálogo com as crianças, na realização de reuniões com os pais de alunos, estabelecendo uma parceria entre a escola e a Associação.

No processo de luta pela escola no Assentamento identificamos duas dinâmicas importantes: o papel da parceria e o protagonismo das mulheres para a construção da escola. O apoio de parceiros ao processo de formação do Assentamento sempre esteve presente durante todo o tempo. As lideranças da comunidade destacam duas instituições que contribuíram na fase inicial do assentamento para que pudessem se aproximar do debate sobre a Educação Contextualizada: O projeto Dom Helder Câmara ${ }^{10}$ e a Universidade Camponesa $\mathrm{UNICAMPO}^{11}$.

\footnotetext{
${ }^{10} \mathrm{Na}$ sua essência, o Projeto Dom Helder Câmara é um programa de ações referenciais de combate à pobreza e apoio ao desenvolvimento rural sustentável no semiárido do Nordeste, embasado no conceito de convivência com o semiárido, articulando às dimensões sócio-políticas, ambientais, culturais, econômicas e tecnológicas e por processos participativos de planejamento, gestão e controle social (Projeto Dom Helder).

${ }^{11}$ A Universidade Camponesa "funciona como uma "rede", em torno das Instituições Federais de Ensino Superior (IFES), a fim de mobilizar as universidades de modo que estas assumam realmente o seu papel públicode formação do conjunto da população". Sua implantação no Cariri da Paraíba, em 2005, teve a finalidade de dialogar com as características geográficas da referida microrregião, no que tange às características físicas e sociais e econômicas, além das experiências bemsucedidas com relação à Escola Agrícola de Sumé e suas práticas junto às comunidades rurais do referido município. A implantação da Universidade Camponesa no
} 


\title{
novist

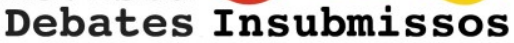

O Projeto Dom Helder acompanhou todo o processo de formação do Assentamento, por meio de um escritório que funcionava no município de Monteiro, no qual seus técnicos de forma sistemática coordenavam cursos de capacitação para os assentados que tiveram o papel de auxiliar na organização da Associação e das atividades produtivas pelos assentados.

Uma das ações do Projeto foi à formação continuada dos/as professores/as. Uma das professoras participou da capacitação ofertada pelo Projeto Dom Helder, que coordenava a formação na modalidade de Educação de Jovens e Adultos (EJA) na comunidade. Conforme a mesma,

\begin{abstract}
Através dessa capacitação que estava fazendo, desse curso de alfabetização, a gente conheceu a orientadora pedagógica do projeto Dom Helder. Ela era do Ceará. E ela perguntou um dia pra mim qual era a maior dificuldade que o assentamento tinha o que era que o assentamento mais precisava? Eu disse a gente precisa de uma escola, porque não faz sentido nossos alunos saírem do sítio para estudarem na cidade e ainda que eles façam um trajeto de mais de quase uma hora... uma semana depois pai foi também pra um encontro também lá no Ceará, pra uma roda de aprendizagem e ela fez a mesma pergunta a pai, que pai é o presidente da Associação. Ela disse assim: seu Anselmo qual é a maior dificuldade que o assentamento tem hoje? Aí ele disse uma escola. Então a partir destes questionamentos [...] aí o projeto Dom Helder começou a realmente investir nesse projeto da escola (Professora do Assentamento).
\end{abstract}

No caso do ProjetoUnicampo, foi destacada no relato a participação de lideranças do Assentamento no Curso de Extensão oferecido sobre Desenvolvimento Sustentável e Convivência com o Semiárido, que estabeleceu um vínculo entre o assentamento e a universidade no desenvolvimento de atividades de campo, de pesquisa e formação no assentamento, é o que mostra o relato a seguir:

\begin{abstract}
Houve um projeto de extensão que foi da universidade camponesa [...] onde a gente fez parte, que ajudou muito na organização do Assentamento. Professor Márcio Caniello, Tonneau, Alexandre, Eduardo, ajudou muito na formação da gente também, na questão de trabalhar as lideranças, as políticas públicas [...] foi um curso de extensão de quatro anos a gente trabalhou. Eu sei que foi muito bom pro Assentamento, porque eles vinham lá pro assentamento, fazer reuniões, chamava o povo, fazia pesquisa. Foi muito bom pra o Assentamento (Liderança Assentada).
\end{abstract}

O envolvimento com o curso possibilitou a formação das lideranças que passaram a buscar organizar a comunidade em torno das mobilizações e reivindicações feitas pelo grupo, e introduziram o debate sobre a questão da Escola, e sua importância dentro da comunidade região contribuíram para a fundação do Centro de Desenvolvimento Sustentável do Semiárido (CDSA). 


\section{Revista (O) \\ Debates Insubmissos}

assentada, com uma organização do trabalho pedagógico contextualizado a luta pela terra, a vida no assentamento, a produção da agricultura familiar e a convivência com o semiárido.

Uma das lideranças que fazia o curso e que tinha filhos/as estudando na sede do município pautou a discussão na comunidade e na Associação, e iniciou o processo de mobilização e debate sobre as implicações do deslocamento das crianças para estudarem na sede do município, inclusive as que precisavam frequentar a Educação Infantil.

No ano de 2008, a comunidade realizou várias discussões para construção de uma escola no Assentamento, como demonstra o depoimento abaixo:

[...], nas reuniões de assembleia as mulheres colocavam essa problemática, eu disse, - Então, vamos fazer o seguinte: a gente tem os filhos, a gente somos mães, se a gente comprar à luta da escola a gente consegue (Fala da Liderança Assentada).

A necessidade das mulheres terem seus filhos e filhas na escola, de uma escola que fosse próximo às suas residências, que não acarretassem em deslocamento das crianças em transporte escolar, com riscos no que se referem ao tempo, as condições de estradas, a precarização dos transportes, mas principalmente, do direito de ter a escola pública na comunidade, no assentamento, com a participação da comunidade, com uma proposta que dialogasse com a vida na comunidade assentada.

Neste sentido, são evidenciados dois elementos principais que desencadearam a mobilização dos moradores. O primeiro, diz respeito à consciência das mães, com relação à preocupação emgarantir um espaço de formação do saber próximo de suas residências e o segundo, diz respeito à consciência das lideranças, que após um processo de sistematização do conhecimento em espaços da educação não formal, assumem a escola como um direito dos sujeitos campesinos, o que reforça a afirmação de Gohn (2006, p. 29), quando diz que: "a educação não formal capacita os indivíduos a se tornarem cidadãos do mundo, no mundo. Sua finalidade é abrir janelas de conhecimento sobre o mundo que circunda os indivíduos e suas relações sociais".

Nesse momento, começam a aprofundar também a discussão sobre a Educação do Campo, com seus princípios, fundamentos e metodologias, e sua contribuição para a identidade campesina, conforme identificamos na fala a seguir: 


\section{novist

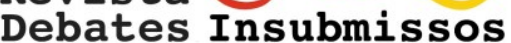

[...], a gente também já vinha discutindo o processo de educação do campo, o que era que a gente queria pra os meninos dá gente? Era vim pra rua e não ter orgulho dá gente, de ser do campo, a gente sempre discutia essas coisas, porque é muito descriminado o fato de morar no campo (Fala de Liderança do Assentamento).

De acordo com uma liderança do assentamento, em dezembro de 2008, através da Associação do Assentamento, foi realizada uma reunião, em que foram convidados os representantes das Secretarias de Educação dos Municípios, participaram apenas Amparo e Prata.

A Secretaria do Município da Prata se prontificou em garantir as matrículas dos estudantes da Agrovila Laginha, que possuía vínculo com o referido município na própria comunidade. Entretanto, em 2009 as mães da referida Agrovila buscaram a secretaria do município da Prata para cumprir o acordo celebrado em assembleia, porém, de acordo com as professoras e lideranças, a solicitação da escola foi negada pelo órgão municipal que alegou falta de estrutura para o funcionamento de uma escola na localidade.

A ação negada pelo poder público municipal mobilizou as mães a buscarem alternativas junto ao ministério público, como relata uma liderança:

[...], isso era mãe chorando pra um lado, o presidente da associação reunido junto com a diretoria da associação [...] então eu disse olhe vamos para o promotor? Se a gente for pra o promotor e o promotor disser que a escola pode funcionar ele vai dar um jeito. Aí nós tava com a norma de educação do campo, a partir de 15 alunos pode ser aberto uma sala na zona rural [...] a gente formou um grupo de mães, as mães são muito determinadas [...] porque elas compraram a briga mesmo. Aí chamemos o promotor lá [...] Levamos o promotor, as mães foi quem conversaram com o promotor, aí o promotor disse: se tiver uma casa que a escola funcione eu vou olhar essa casa e vocês já pode começar hoje [...] aí eu disse, tem a minha [...] eu disse - vamos olhar, ele foi olhar e disse pode funcionar aqui. [...] eu disse, agora vamos lá falar com painha, se painha der o armazém pra gente botar os troços e a gente morar lá, aí painha deu e as meninas já começou a preparar a escola (Liderança do Assentamento).

O relato demonstra a luta das mães que buscaram várias instâncias do poder para conseguir a efetivação de suas lutas, onde o conflito esteve em torno do direito à escola na comunidade, que segundo os moradores havia mais estudantes do que o previsto para se instalar uma sala na localidade. As atrizes sociais desta resistência eram as mães, tornando-se autora das ações que foram sendo desencadeadas junto à comunidade. 
Após garantirem o espaço, inicia-se uma nova luta, essa no intuito de garantir a efetivação das matrículas das crianças, haja vista que a comunidade não dispunha da aprovação do poder executivo. Na época, houve a transição do governo do Estado, onde José Targino Maranhão, que assumiu o governo do Estado, por motivo da cassação do então governador Cássio Cunha Lima. De acordo com uma das lideranças do Assentamento, o atual prefeito do município da Prata, que na época fazia oposição àgestão municipal, mas, por ser aliado político do novo governador conseguiu o apoio do Estado para a efetivação das matrículas dos estudantes, pois havia no município a Escola Estadual de Ensino Infantil e Fundamental Plínio Lemos, que atendia alunos do primeiro ciclo do Ensino Fundamental.

As disputas política partidárias e as divergências nas diferentes esferas do poder público, gera diferentes negociações e enfrentamentos que se efetivam entre poder público e sociedade civil no que se refere a luta pela escola nas comunidades rurais, o que possibilita muitas vezes espaços para a ação dos movimentos e organizações. Isto possibilitou a abertura de matriculas das crianças, o funcionamento inicial improvisado na casa de uma moradora, e a mobilização das mulheres para construção da escola.

Durante o ano letivo de 2009, as despesas com a educação foram arcadas pelos pais dos alunos no que se refere à merenda e ao material didático. A comunidade conseguiu junto ao Estado a contratação de duas professoras, porém, de acordo com a atual diretora da Escola, na época os salários atrasavam o que resultou na desistência das professoras em continuar trabalhando. Foi quando ela e outra professora da escola, que na época estavam cursando licenciatura substituíram as antigas professoras, dividindo um único contrato entre ambas.

Neste ano de 2009, a Associação teve acesso a um financiamento do FIDA ${ }^{12}$ através do Projeto Dom Helder para obras de infraestrutura no Assentamento e a esperança de construção de uma Escola que atendesse a Educação Infantil e os anos Iniciais do Ensino Fundamental foi se tornando realidade.

\footnotetext{
${ }^{12} \mathrm{O}$ Fundo Internacional de Desenvolvimento Agrícola (FIDA) é uma organização internacional ligada a Organização das Nações Unidas (ONU). A referida organização tem por finalidade fomentar financiamento direto junto a instituições que tem como finalidade o desenvolvimento social e econômico de comunidades pobres situadas em áreas rurais
} 


\section{Revista \\ Debates Insubmissos}

Entretanto, para que a escola fosse construída, seria necessária a colaboração entre a prefeitura e o financiamento do projeto Dom Helder, onde a prefeitura se responsabilizaria com a contrapartida da mão de obra para a assinatura do convênio, os moradores buscaram junto ao gestor do município a parceria, que mais uma vez foi negada pelo mesmo. Na ocasião a decisão tomada entre a comunidade e a equipe do projeto foi que a comunidade ofertasse a contrapartida pré-estabelecida pelo projeto. Conforme nos evidencia a fala abaixo:

Quando a gente comprou a cobertura: telha e madeira sobraram muito pouco do recurso, então a gente começou a trabalhar, os pedreiros vieram de graça, porque a gente conseguiu os pedreiros com um amigo nosso e alguns pais trabalharam de graça. E pra conseguir construir a escola de verdade, as mães foram as que deram a maior força, porque elas carregaram até as pedras na cabeça e quando a gente tava na metade da construção faltou todo tipo de material, então a gente começou a pedir, as mães foram pra rua, os pais que trabalhavam ajudaram também, um dava um saco de cimento, um dava outra coisa [...] a gente conseguiu ajuda com outras pessoas de fora e foi assim que a gente construiu a escola. (Professora da Escola).

A autoria das mulheres assentadas - mães, lideranças e professoras - se destaca em todo o processo. As mães se colocaram enquanto atrizes desta conquista, que em meio a tantos conflitos institucionais se sobressaíram através da mobilização e da força social da comunidade, que buscaram alcançar seus objetivos e não se submeteram as imposições de interesses do poder público, pois mesmo em condições adversas, de negação, precariedade de infraestrutura e escassez de recursos não desistiram e mostraram que, se há mobilização e interesse coletivo as dificuldades são superadas e os objetivos começam a se efetivar.

A luta pela construção da escola, na comunidade de Laginha deve ser entendida enquanto um movimento formado por mulheres, que almejavam um lugar para que seus filhos/as estudassem, sem haver o deslocamento das crianças, que segundo elas, punha em risco a integridade física dos mesmos, conforme nos mostra o depoimento abaixo:

$[\ldots]$ eu fico imaginando o transporte pra rua $[\ldots]$ é muito boa à escola da rua porque quem estuda lá aprende, mas só que a gente fica com aquela preocupação entendeu? No tempo do inverno mesmo, esse ônibus atola na estrada, a gente já fíca doido, quando começa a chover as mães já fica preocupada e aqui não, os meninos tem toda chance e aprende outras coisas diferentes (Assentada B).

O acesso ao conhecimento sobre a legislação e os direitos da escola do campo também foi importante, pois as lideranças da comunidade buscaram alternativas para alcançar os objetivos traçados e o direito dos assentados, conforme reza à legislação da Educação do 
Campo, em seu "Art. $3^{\circ}$ : A Educação Infantil e os anos iniciais do Ensino Fundamental serão sempre oferecidos nas próprias comunidades rurais, evitando-se os processos de nucleação de escolas e de deslocamento das crianças".

A constituição de coletivos de trabalho, a auto-organização e autogestão da comunidade suscitaram processos educativos escolares e não escolares dentro do Assentamento, construindo uma relação de parceria e diálogo entre a escola e a comunidade.

O que identificamos na revisão da literatura é que este processo de luta e construção da escola nas comunidades ocorre em diferentes espaços brasileiros, estimulado pelo Movimento Nacional da Educação do Campo, colocando na agenda política do país pelos movimentos sociais campesinos.

A luta pela escola no Assentamento originou-se e se tornou realidade a partir do movimento idealizado pelos moradores, mas é necessário que continue a movimentar-se e que os sujeitos possam fazer parte deste movimento num constante processo de formação política, através do processo de conscientização dos sujeitos, onde os saberes sistematizados e em sistematização possam nortear a prática pedagógica na associação, na escola construída, na política e que essa luta, tal qual o movimento da e por educação do campo seja constante.

Se for assim, ajudar a construir escolas do campo é, fundamentalmente, ajudar a constituir os povos do campo como sujeitos, organizados e em movimento. Porque não há escolas do campo sem a formação dos sujeitos sociais do campo, que assumem e lutam por esta identidade e por um projeto de futuro.

A comunidade necessita avançar no processo de socialização dos conhecimentos que há entre o grupo, que são ricos e capazes de serem renovados e aprimorados, para que os pais, estudantes, pessoas com mais idade, professores e a organização, possam contribuir na continuidade da luta e de posse dos saberes acumulados pelas lideranças, identificando o real sentido da educação do campo no Assentamento Zé Marcolino, que está muito além de se ter uma escola próxima da residência das crianças. Portanto a continuidade da luta necessita ser descentralizada para que as pessoas possam lutar pela educação do campo e não apenas por uma escola no campo. 
Uma escola do campo não é, afinal, um tipo diferente de escola, mas sim é a escola reconhecendo e ajudando a fortalecer os povos do campo como sujeitos sociais, que também podem ajudar no processo de humanização do conjunto da sociedade, com suas lutas, sua história, seu trabalho, seus saberes, sua cultura, seu jeito.

A educação e a história da educação na comunidade necessitam servir de inspiração para que as pessoas da localidade passem a buscar a sistematização do conhecimento através da escrita, para que elas não se envergonhem em responder um questionário por não ter a capacidade de realizar a leitura das letras, portanto é necessário um trabalho de formação de base para que o verdadeiro sentido da luta pela escola seja compreendido por todos os moradores e consequentemente os mesmos possam continuar sua luta por educação do e no campo.

Portanto, é necessário que a educação seja libertadora, não apenas para a comunidade escolar, mas para toda a comunidade no seu entorno, possibilitando aos mesmos uma visão crítica do mundo, gerando a consciência de suas ações enquanto sujeitos, possibilitando que os mesmos saiam da condição imersa que lhes foi introduzida historicamente, pois se percebe que os sujeitos estão imersos"no mundo, no seu estar, adaptado a ele e sem ter dele a consciência (FREIRE 1997. p 19)", ou seja, os moradores viveram a luta pela escola, passado essa fase parece que agora isso é uma questão dos que atuam nela, deixa de ser algo a ser tratado pela comunidade - os assuntos da educação passam a ser dos que atuam na educação, e não de toda a comunidade.

\section{CONSIDERAÇÕES}

Esta pesquisa, que teve como objetivo geral mapear a formação e organização do Assentamento na luta pela terra e pela escola, e qual a percepção que os diferentes sujeitos: lideranças, professoras e assentados tem sobre o papel da escola na comunidade, possibilitou uma série de desafios e aprendizados para minha formação acadêmica, pessoal e política.

Primeiro, pelo desafio da aproximação com o campo da pesquisa, constituído por pessoas, que assim como eu, trabalhadores e trabalhadoras do campo, lutadores e lutadoras 
para permanecer produzindo na terra aqui no Cariri Paraibano. A conquista da confiança das pessoas, a aproximação com seu contexto, o entendimento da dinâmica do grupo e a sistematização das conversas informais, certamente, desafiaram meus conhecimentos sobre as metodologias de pesquisa. Todavia, fazer isto, sem deixar que a emoção de ver a luta e as dificuldades que ainda enfrentam mesmo na posse da terra, os desafios na relação entre as lideranças e a base foi a mais difícil tarefa que enfrentei como pesquisador e liderança de uma organização.

Segundo, a dificuldade de acessar os documentos para analisar a história da organização da luta, me evidenciou a fragilidade existente nas organizações rurais e entre os camponeses de registrar e sistematizar os seus itinerários de lutas, bem como de dar visibilidade aos sujeitos envolvidos em cada momento das mesmas. O que coloca mais um desafio para a Escola do Campo, de como contribuir nesse processo de reflexão sobre a importância do registro da memória. Esse fato redirecionou o uso de um procedimento que tinha sido pensando inicialmente para a pesquisa que era a análise documental sobre a formação e estruturação do assentamento. Essas informações acabam ficando com os órgãos governamentais e/ou organizações não governamentais que atuam na área, e não é apropriado pelos assentados.

As conversas e os relatos informais das lideranças e dos assentados foram me permitindo aos poucos conhecer a história, o contexto social e político do assentamento, o que trouxe como procedimentos principais da pesquisa: a aplicação de questionário para traçar o perfil dos sujeitos e as entrevistas para entendimento de sua percepção sobre os acontecimentos que estavam sendo estudados.

Alguns achados da pesquisa nos reafirmaram a complexidade da questão da luta pela terra, no Cariri Paraibano, decorrente de como a questão agrária foi se estruturando ao longo dos anos, e as relações sociais que foram se estabelecendo entre as classes sociais aqui na região: fazendeiros, posseiros, sem-terra, agricultores familiares, e outros que foram surgindo depois (e que não objeto do estudo no momento), pescadores, ribeirinhos dos açudes. A forma como a terra foi sendo apropriada por poucos para o criatório do gado bovino gerou não 


\section{Revista \\ Debates Insubmissos}

somente relações de poder e exploração das pessoas, mais também uma devastação da Caatinga e das fontes de água da região.

Os camponeses e as camponesas são protagonistas de suas histórias, e resistiram às tentativas de expropriação da terra e contra o capitalismo perverso. Contudo, as relações são constituídas em processo conflituoso e ideológico, em meio a estes conflitos a injustiça e a miséria gerada pela concentração de riqueza por uma minoria e a omissão do Estado suscitaram também diferentes formas de organização e representação social, que possibilitou sua resistência ao modelo de modernização conservadora que expropria os trabalhadores e trabalhadoras do campo para inserir o modelo produção da monocultura e a exploração dos camponeses, bem como, a resistência contra a opressão da ditadura civil-militar, do modelo neoliberalista e da mecanização e mercantilização da terra e da agricultura, que excluiu e reprimiu perversamente as organizações sociais dos trabalhadores e trabalhadoras do campo.

O processo de ocupação da Terra suscitada pelo Estado, inicialmente, com a inscrição no correio, teve uma parcela de contribuição do Movimento Social para ocorrer, devido à própria burocracia do Estado, que não agilizava o processo de desapropriação e a posse das famílias. Isso também contribuiu para que o grupo entrasse na terra, com a mentalidade de pressionar e reivindicar do Estado outras políticas públicas, como: saúde, moradia, educação, políticas agrícolas, o que tem sido feito de forma sistemática pela Associação do Assentamento.

O processo educativo da Educação do Campo, primeiro na sua dimensão não formal, foi o pontapé inicial para a comunidade começar a perceber a importância da Educação para sua organização, produção e vida. E por isto, destacou-se a ação formativa desenvolvida pelo Projeto Dom Helder e a Unicampo no Assentamento.

A autoria das mulheres na luta pela Escola foi outro achado importante da pesquisa, que construiu a escola a partir de um projeto em parceria com o Projeto Dom Helder, salientamos ainda, que a organização da comunidade possibilitou a formação de mutirões para a construção da escola, bem como para conseguir recurso no comércio local para complementar o recurso utilizado para construir o prédio. Isso evidenciou não apenas seu 


\section{Revista $(0)$ \\ Debates Insubmissos}

papel como mães, mais também como assentadas que começaram a perceber a importância de se ter uma escola perto de sua casa, para que seus filhos e filhas pudessem estudar no assentamento, e como a ação coletiva e a mobilização contribuíram para as conquistas. Hoje o desafio é esse debate continuar sendo aprofundado com todas as famílias assentadas na perspectiva de fortalecimento do projeto político pedagógico da escola.

Destacamos a importância da escola para a comunidade assentada, e o fator da escola está perto do lugar onde vivem as crianças, o que reforça os laços de pertencimento, o sentimento comunitário e ao mesmo tempo a presença da instituição pública no espaço do assentamento. Estas categorias são essenciais para compreender o sentido atribuído pelos moradores com relação à escola, pois para as famílias citadas a relação com a escola e o convívio dos educandos no ambiente de origem contribuiu para a formação da identidade destes sujeitos aos valores culturais da família.

Entretanto, a comunidade vivencia vários desafios referentes ao processo de reconhecimento da escola enquanto escola do campo, que como demonstrado na pesquisa a mesma funciona com o nome "emprestado" de uma escola da sede do município da Prata-PB que foi fechada. Esta ação tem outra finalidade que é a respeito do vínculo da escola, pois há a incerteza se a mesma continua vinculada ao estado ou ao município, a pesquisa nos revelou que já existe uma pauta por parte das lideranças e professoras, junto às secretarias de Educação do Município e do Estadocom a finalidade de serem discutidas tais propostas, no entanto, percebe-se que esta ação está centralizada nas lideranças.

Outro ponto destacado para continuidade da reflexão diz respeito aos assentados que, em parte, não se identificam com a conquista da escola e evidenciam que a importância da mesma consiste em está localizada próximo das residências dos educandos. Há na comunidade pessoas que declaram ser analfabetas e uma grande maioria que afirmam ter o grau de ensino fundamental incompleto, mas durante a aplicação dos questionários afirmaram que pouco sabem escrever, esta realidade demonstra o desafio da comunidade para que os mesmos não sejam sujeitos apenas da escola, mas da escolarização, da emancipação, através da sistematização dos saberes, para que os mesmos atuem de forma crítica nas ações da 


\section{Revista (O) \\ Debates Insubmissos}

comunidade. Tal desafio tem como possibilidade a conscientização das pessoas a participarem da Educação de Jovens e Adultos que há na escola da comunidade.

Uma questão posta para as lideranças do Assentamento é de como construir novas formas de socialização, partilha e registro dos conhecimentos, lutas e conquistas da comunidade, na perspectiva de fortalecimento da democratização das relações com as famílias assentadas, do pertencimento e identidade política do assentamento, e para que os assentados continuem sendo os protagonistas de suas histórias, lutas e conhecedores dos seus direitos na conquista de políticas públicas e sociais para a comunidade.

A formação para a ação política bem como para a organização produtiva precisa ser realizada de forma articulada, para que os associados não vejam a Associação apenas com o papel de captação de recursos para o Assentamento, mas como o instrumento de articulação, mobilização e luta pelos direitos.

A contribuição que este estudo pode trazer para a comunidade assentada é no sentido de se refletir sobre o papel dos diferentes sujeitos, e a necessidade de uma maior articulação entre os processos educativos formais e não formais no Assentamento, de maneira que os saberes e os fazeres do campo possam ser socializados entre lideranças, professores e assentados. Portanto, se faz necessário um processo de formação de base, visando descentralizar os saberes/fazeres das lideranças e professores, para os demais moradores da comunidade, com a finalidade de ampliar as concepções sobre o sentido da organização e da educação do campo na comunidade.

A contribuição para o Curso de Educação do Campo é de reforçar a importância dos estudos sobre a questão agrária no Brasil e no Cariri, sobre as formas de organização social do campo na região, como forma de entender que é neste lugar que se constrói a Educação e a prática docente do Curso, e que deveria orientar o ensino, a pesquisa e a extensão do Centro de Desenvolvimento Sustentável do Semiárido, que nasceu a partir desta experiência educativa desenvolvida pela Unicampo no território do Cariri junto aos camponeses e camponesas. 


\section{REFERÊNCIAS}

ARROYO, Miguel Gonzalez; FERNANDES, Bernardo Mançano. A educação básica e o movimento social do campo.Brasília DF: Articulação Nacional por uma Educação Básica do Campo, 1999. Coleção por uma Educação Básica do Campo, n 2. Pag 05 a 15

CALDART, Roseli Salete.Por Uma Educação do Campo: traços de uma identidade em construção in educação do campo identidades e políticas públicas. Brasília, DF: Articulação Nacional por uma Educação do Campo, 2002. Coleção Por Uma Educação do Campo, n. ${ }^{\circ} 4$. Pag. 18 a 25.

CALDART. Caminhos para transformação da educação. In: temas e problemas no ensino em escolas do campo. $1^{\text {a }}$ ed._São Paulo. 2012. Pág. 23 a 57.

ENGELS, F. Carta a Bloch. In: MARX, K; ENGELS, F. Obras escolhidas. V. 3. São Paulo: Alfa-Ômega, 1986.

FERNANDES, Bernardo Mançano. Por uma educação básica do campo. IN: A educação básica e o movimento social do campo. Brasília DF: Articulação Nacional por uma Educação Básica do Campo, 1999. Coleção por uma Educação Básica do Campo, n 2. Pag. 55 a 70.

FERNANDES.Bernardo Mançano. Os campos da pesquisa em educação do campo: espaço e território como categorias essenciais. Educação do campo e pesquisa: questões para reflexão. Brasília, MDA, 2006.

FREIRE, Paulo. Educação e mudança. 2 2 ed. rev. e atual. São Paulo. Paz e Terra, 2011.

FREIRE. Pedagogia do oprimido, 17 . Ed. Rio de Janeiro. Paz e Terra, 1987.

GOHN, Gloria. História dos movimentos e lutas sociais: a construção da cidadania dos brasileiros. São Paulo: Loyola, 1995.

GOHN. Movimentos sociais, cidadania e educação. In: Movimentos Sociais e Educação. 6. Ed. Revista. São Paulo: Cortez, 2005.

GOHN. Teorias dos movimentos sociais: paradigmas clássicos e contemporâneos 6. ed. São Paulo Loyola 1997.

JULIÃO, Francisco. Quem são as Ligas Camponesas? In: Camponeses brasileiros: leituras e interpretações clássicas. Vol. 1_ São Paulo Editora UNESP. Brasília, DF. 2009. Pág.271 a 297.

MINAYO Maria Cecília de Souza. O Desafio do Conhecimento: Pesquisa Qualitativa em Saúde. 4ed. São Paulo. HUCITEC-ABRASCO. 1996.

PALUDO, Conceição. Educação Popular em busca de alternativas: uma leitura desde o campo democrático popular. - Porto Alegre: Tomo Editorial; Campo, 2001. 
SILVA, Maria do Socorro. Da raiz a flor: produção pedagógica dos movimentos sociais e a escola do campo. In: Educação do campo e pesquisa: questões para a reflexão. Brasília. Ministério de Desenvolvimento Agrário. 2002. Pag. 60-92.

SILVA. Maria do Socorro.Educação do Campo e Desenvolvimento: uma relação construída ao longo da história. CONTAG. Brasília DF. 2007.

SILVA. Maria do Socorro.As práticas pedagógicas das escolas do campo: a escola na vida e a vida como escola. Tese de Doutorado em Educação. UFPE: Recife, 2009.

TERENCE, Ana Cláudia Fernandes e ESCRIVÃO FILHO Edmundo Abordagem quantitativa, qualitativa e a utilização da pesquisa-ação nos estudos organizacionais. XXVI ENEGEP - Fortaleza, CE, Brasil, 9 a 11 de outubro de 2006.

Submetido em: 16/03/2019

Aprovado em: 26/06/2019 